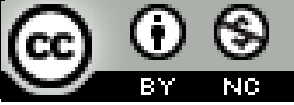

\title{
O VALOR DA CIÊNCIA: O DEBATE ENTRE A CONCEPÇÃO EPISTÊMICA E O REDUCIONISMO UTILITARISTA NA FILOSOFIA DA CIÊNCIA DE ILLKA NIINILUOTO
}

\author{
The value of science: The discussion between the epistemic conception \\ and the utilitarian reductionism in philosophy of science of $11 k$ ka Niiniluoto
}

\author{
Vinicius Carvalho da Silva \\ UERJ/UFT
}

\begin{abstract}
Resumo: No presente artigo analisamos o debate entre duas concepções de ciência. De um lado, temos o que vamos chamar de imagem epistemicista, conforme a qual a ciência possui um valor intelectual e cultural intangível, e por isso é um fim em si mesmo. Tal concepção pode ser atacada como cândida, como se defendesse uma imagem de ciência como "Torre de Marfim". Do outro temos uma imagem de ciência que reduz a pesquisa científica a um meio para alcançarmos fins práticos, como desenvolvimento tecnológico e econômico e progresso social. Sendo assim, a chamamos de reducionismo utilitarista. Buscaremos compreender o debate, e propor como a filosofia da ciência contemporânea deve se posicionar ao participar dele.
\end{abstract}

Palavras chave: Axiologia, Valores, Ethos Científico, Utilitarismo

\begin{abstract}
In the present article we analyze the debate between two conceptions of science. On the one hand, we have what we will call an epistemic image, according to which science has an intangible intellectual and cultural value, and therefore is an end in itself. Such a conception can be attacked as candid, as if defending an image of science as "Ivory Tower". On the other we have an image of science that reduces scientific research to a means to achieve practical purposes, such as technological and economic development and social progress. Therefore, we call it utilitarian reductionism. We will seek to understand the debate, and to propose how the philosophy of contemporary science should position itself by participating in it.
\end{abstract}

Keywords: Axiology, Values, Scientific Ethos, Utillitarianism.

\section{Introdução}

No debate contemporâneo em filosofia da ciência a questão do valor da pesquisa científica é um objeto de análise e controvérsias. Mas o debate não é novo. Ao longo da história das ciências duas concepções de natureza e ciência se tomaram tradicionais. Vamos chamar tais concepções de epistemicismo e utilitarismo. Este último não deve ser confundido com a escola de filosofia moral britânica. O pressuposto metafísico básico do epistemicismo seria a realidade objetiva do mundo. O real, que existe de modo ordenado e inteligível independente de nós, pode ser compreendido pela razão. A busca da verdade seria a mais nobre tarefa da ciência, o seu valor, propriamente dito. Conforme Popper, esse é o traço característico do essencialismo filosófico de Galileu (Popper, 1980)ํ.Já a imagem utilitarista se funda em uma concepção de natureza como algo a ser conquistado e utilizado para satisfazer necessidades práticas e a ciência como o melhor instrumento para levar a cabo essa conquista.

${ }^{1}$ POPPER, Karl. Três concepções sobre o entendimento humano in "Os Pensadores". Trad. Pablo Ruben Mariconda e Ruben de Almeida. São Paulo: Abril Cultural, 1980.p. 134 
Físicos filósofos como Heisenberg e Schrödinger defenderam formas de epistemicismo, negando que a ciência se reduza à técnica e que seu valor possa ser medido conforme critérios utilititários, práticos, produtivos e econômicos. A ciência seria uma atividade espiritual, uma nobre realização intelectual, e suas conquistas, portanto, engrossariam o caudal da cultura, criando uma cosmovisão com a qual nos identificamos e a partir da qual tentamos compreender o mundo e a nós mesmos. Conforme Planck, a busca do absoluto é o objetivo supremo da atividade científica (PLANCK, 2012)2 . O cientista deve ser inspirado pela busca da verdade absoluta. Mas deve saber que se trata de uma busca sem fim. A verdade deve ser seu ideal, não seu ídolo, sua ilusão. Poderemos nos "aproximar" da verdade. Jamais conquistá-la. Como demonstramos em Teoria quântica, física nuclear e filosofia grega: ensaio sobre os físicos filósofos do século $X X$, físicos filósofos como Heisenberg e Schrödinger foram severos críticos do utilitarismo. Tal concepção de ciência se fundamenta em uma imagem da natureza como algo a ser dominado e controlado a fim de arrancarmos seus segredos, e nos utilizar destes para produzir utilidades práticas, bens de capital, riquezas.

Um interlocutor hipotético poderia objetar que a imagem epistemicista é aquela de uma Torre de Marfim, já superada pelos estudos de ciência, sobretudo pela nova sociologia da ciência, pela nova filosofia da ciência, pela história das ciências da segunda metade do século XX, os construtivistas sociais, o Programa Forte, os science studies, as pesquisas etnográficas centradas no laboratório e no experimento, na ciência "tal como é feita". O epistemicismo seria uma "flor de estufa" que ainda encontrou vida até Popper, mas que já em Kuhn começou a definhar, até ser completamente abandonada quando os novos estudos de ciência revelaram a pesquisa científica como uma construção social, histórica, local, impactada por fatores políticos, econômicos e institucionais e moldada pelo dia a dia de seus praticantes. Mas a virtude de nosso interlocutor hipotético seria comparável a de Dom Quixote ao vencer moinhos de vento. O epistemicismo de Planck, Heisenberg ou Schrödinger, dentre tantos outros, não deve ser simploriamente reduzido à imagem da Torre de Marfim. Tais físicos filósofos defendiam uma imagem realista de natureza e concebiam a ciência como uma busca filosófica pela verdade, mas estavam igualmente cientes dos problemas filosóficos de uma teoria da verdade e da filosofia da natureza. Eles pensavam a ciência como uma atividade histórica, social, atravessada por fatores políticos, econômicos e institucionais. Não negavam a importância da técnica, da aplicação da ciência ao mundo da produção, enfim, não criavam uma falsa dicotomia entre verdade e utilidade, tampouco consideravam a ciência como um mundo a parte, acima da sociedade, da política, dos locais e práticas de produção do conhecimento científico. Não pensavam a ciência como uma atividade etérea atemporal, mas como um conjunto de práticas históricas. O epistemicista cândido que confunde a "busca da verdade" com a vida em uma Torre de Marfim não é o nosso físico filósofo, mas sua caricatura.

Para tais físicos fillósofos a contradição, portanto, não era entre verdade e utilidade, ou entre ciência e técnica, mas entre duas cosmovisões distintas, duas filosofias da natureza divergentes, com metafísicas e ethos inconciliáveis, duas respostas controversas para a questão do valor da ciência. De um lado uma concepção de ciência como busca da verdade ${ }^{3}$, do outro, uma concepção de ciência como modo de dominação e controle da natureza. O epistemicismo não se opõe à técnica, ao desenvolvimento

\footnotetext{
2 PLANCK, Max. Autobiografia científica e outros ensaios. Tradução Estela dos Santos Abreu. Rio de Janeiro: Contraponto, 2012.

${ }^{3} \mathrm{O}$ que, como já vimos, não nega a ciência como prática histórica e social e nem nega a centralidade da técnica para a sociedade modema. Tal epistemicismo admite também que, enquanto atividade complexa, a ciência abriga tensões, conf́litos de interesses e disputas de natureza psicológica, social, política e econômica. Quando o epistemicista diz que a ciência é a busca da verdade está dizendo que esse deve ser um valor central para o ethos científico, ou seja, está sustentando a importância dos valores para as práticas científicas. Em outras palavras, está defendendo que a ciência não é neutra - e já que a ciência possui um pano de fundo axiológico e está aberta à influência de ideologias e interesses diversos, o epistemicista, ao defender a "busca da verdade", participa do debate epistemológico e político sobre o valor do conhecimento científico e se mostra ativo nessa tarefa de imprimir à ciência um objetivo, de pautá-la a partir de determinados valores.
} 
tecnológico, ao progresso industrial, econômico, mas se nega a considerar que a natureza e a importância da ciência se encontram subordinadas a tais coisas. Logo, não há dicotomia entre a concepção epistêmica de ciência, a relação mutuamente enriquecedora entre ciência e técnica, e a importância da tecnologia para o incremento da base material das sociedades. O utilitarismo não está no desenvolvimento industrial, tecnológico, no aperfeiçoamento dos modos de produç̧̃ă, mas na ideologia de que esse é o valor da ciência, que é para servir a tais fins que a pesquisa científica deve ser realizadla.

Entre a "Torre de Marfim" e o "Vale das Sombras", existe um espectro complexo com muitas gradações. No dia a dia dos praticantes de ciências, tensões entre aspectos epistemicistas e utilitários se materializam na forma de conflitos de interesses, disputas políticas, busca por autonomia científica, luta por financiamento, embates institucionais etc. O ethos científico é marcado pelas diferenças entre os valores, que nos orientam como a pesquisa deve ser, e os fatos, que revelam como ela é. Filósofos contemporâneos como Ilka Niiniluoto, defendem uma concepção não dicotômica de ciência, sustentando que a pesquisa científica possui um valor cultural que transcende qualquer limitação exclusivamente utilitária ao mesmo tempo em que é um poderoso instrumento de desenvolvimento social e econômico. Cremos que neste ponto a posição de Niiniluoto está plenamente de acordo com aquela defendida por físicos filósofos como $\mathbb{P l a n c k}$, Heisenberg e Schrödinger. Na próxima seção nosso objetivo será compreender melhor o pensamento contemporâneo de Niiniluoto.

\section{A controvérsia entre epistemicismo e utilitarismo na concepção de Niiniluoto}

O debate filosófico acerca da disputa histórica entre as concepções de ciência que estamos chamando de epistemicismo e utilitarismo está presente nos trabalhos do filósofo finlandês Ilkka Niiniluoto da Universidade de Helsinki, autor de Critical scientific realism ${ }^{4}$ (2004), no qual defende uma relação entre o pressuposto metafísico do realismo e a axiologia da pesquisa científica, advogando que ainda é não somente possível, mas necessário, prescrever e não somente descrever o ethos científico. No final do trabalho, quando trata das relações entre ciência e sociedade, o autor levanta a questão "Qual é o valor cultural da ciência?", isto é, por que a ciência é importante para a cultura em si, e não somente para os interesses estratégicos de determinados grupos?

A estratégia dialética de Niiniluoto é confrontar as concepções de ciência de $\mathrm{L}$. J. Cohen e J. D. Bernal, buscando oferecer uma solução que transcenda o conflito flagrante. De acordo com o autor, Cohen oferece um exemplo emblemático de uma concepção de ciência que privilegia suas conquistas epistêmicas aos seus avanços práticos:

Para estudar mais sistematicamente o valor cultural da ciência, é desejável começar pela questão posta por $\mathrm{L}$. $\overline{\mathrm{J}}$. Cohen (1997) que pergunta se ser realista é um dever moral do cientista. De acordo com Cohen, esta conclusão pode ser defendida pelos argumentos que se seguem: (i) se o conhecimento é um fim em si mesmo e (ii) se o realismo é parte da melhor metodologia para obtenção do conhecimento, então (iiii) o cientista possui a obrigação ética de ser realista. (NIINILUOTO. 2004, p. 288) $)^{5}$

A concepção de Cohen do "realismo como obrigação ética do cientista" e nosso pressuposto de que toda metafísica é uma axiologia são consoantes. Assumir uma determinada metafísica da ciência é firmar um compromisso, também, com os deveres morais que devem nortear a prática científica. No caso de Cohen, o realismo é a um só tempo um pressuposto metafísico e um princípio axiológico. Essa imagem de ciência (que busca um conhecimento que é um fim em si mesmo) é diametralmente oposta àquela defendída por Bernal, de acordo com a qual, ressalta Niiniluoto, a ciência é, e deve ser, um meio:

${ }^{4}$ NIINILUOTO, Illka. Critical Scientific Realism. Oxford: Oxford University Press, 2004 ${ }^{5}$ Idem. 
A fim de avaliar a premissa (i) é instrutivo considerar primeiro a visão alternativa, de J. D. Bernal, o conhecido historiador da ciência britânico, um convincente e eloquente defensor da tradição otimista do Iluminismo. A ciência possui um valor cultural, ele argui com Bacon e Marx, desde que sirva como um instrumento eficiente e indispensável para o progresso social (ver Bemal 1939;1969). (NIINILUOTO. 2004, p. 289)

Enquanto Cohen sustenta que o conhecimento científico é um fim em si mesmo, Bernal defende que o conhecimento científico é valioso, se, e somente se, contribui efetivamente para a melhoria prática das condições sociais. É um tipo de 'utilitarismo social'. Em seu The social fuction of science ${ }^{7}$ Bernal reconhece que essas duas posições são extremas. De um lado, temos aqueles que concebem a "ciência como pensamento puro" em busca da verdade, de outro, temos aqueles que a pensam como uma forma de "poder", na qual a "verdade" é aquilo que possibilita a utilidade, o uso prático capaz de transformar as condições de vida das sociedades ${ }^{8}$. De acordlo com Bernal, as raízes da visão de ciência como busca da verdade, uma busca sumamente epistêmica e desprovida de função social, remontam, no mínimo, a Platão:

Those who hold the first view would not admit that science has any practical social function, or would allow at most that the social function of science is a relatively unimportant and subordinate one. The most usual justification which they would give for science is that it is an end in itself, a pursuit of pure knowledge for its own sake. This attitude has played a great and not altogether happy part in the history of science. It was a dominating view in classical times, and was expressed very finely in the words of Plato (BERNAL。1946, p. 4) . $^{9}$

Bernal se refere à passagem do Livro VII de A Repúiblica na qual Platão concebe como o mais sublime valor do estudo nos conduzir à contemplação do eidos, isto é, da forma pura do Bem. Quanto à visão de ciência como poder, controle sobre a natureza e utilização prática de tal poder para o incremento da prosperidade humana, Bernal enfatiza que, embora Roger Bacon (1214-1294) já apontasse nesta direção, foi Francis Bacon (1561-1626) quem primeiro a formulou de modo claro, concebendo "utilidade" e "progresso" como as duas palavras-chave da ciência ${ }^{10}$.

\section{Qual é o valor da ciência?}

Este impasse entre o que significa fazer uma ciência responsável, sobre qual é o valor da ciência e qual é a melhor forma de se fazer com que a ciência sirva à prosperidade humana continua sendo objeto de interesse entre cientistas e estudiosos de ciências. As pesquisadoras Maja Horst e Cecilie Glerup da Universidade de Copenhagen analisaram 263 periódicos científicos e seus artigos sobre a função social da pesquisa científica, a relação entre ciência e sociedade e a noção de responsabilidade dos cientistas. Como os cientistas pensam que é a melhor forma de se praticar ciência? De qual modo a ciência pode ser mais benéfica para a sociedade? Em Mapping 'social responsibility' in science ${ }^{11}$, Horst e Glerup concluem que após analisar todas as 263 fontes especializadas, puderam, em linhlhas gerais, encontrar quatro grandes concepções de ciência e de política científica: os cientistas adeptos da Demarcation rationality

${ }^{6} \mathrm{Em}$ Knowledge and Language, Cohen trata da relação entre realismo e dever moral. Ver: COHEN, Jonathan L. Knowledge and Language. Selected essays. James Logue (Edt). Dordrecht: Klluwer Academic Publishers, 2002. p, 314.

${ }^{7}$ BERNAL, John D. The Social Function of Science. London: George Routledge \& Sons LTD., 1946.

${ }^{8}$ Ibidem, pp.4-12

${ }^{9}$ Tbidem.

${ }^{10}$ Tbidem, p. 6.

${ }^{11}$ GLERUP, C; HORST, M (2014) Mapping 'social responsibility' in science, Journal of Responsible Innovation, $1: 1,31-50$. 
advogam que a melhor maneira da ciência ser responsável é sendo plenamente independente e completamente autorregulada, não sendo afetada por interesses extraepistêmicos, enquanto os partidários da Reflexivity rationality pensam que a ciência deve ser guiada, na escollha de seus problemas e linhhas de investigação, pelas necessidades da sociedade. Um terceiro grupo é formado pelos entusiastas da Contribution rationality que insistem que a ciência deve viver de acordo com as demandas públicas por inovação, por úlitimo, aqueles que sustentam a Integration rationality defendem que a ciência deve ser co-construída por atores sociais a fim de ser socialmente responsável ${ }^{12}$.

Parece que poderíamos classificar Bernal com um adepto da Reflexivity rationality ou mesmo em uma fronteira entre esta e a Contribution rationality, ao passo que Cohen seria melhor situado entre os partidários da Demarcation rationality. Já Niiniluoto se encontraria em uma suporposição entre a Demarcation rationality e Integration rationality. A ciência, de acordo com Bernal, é um meio epistêmico para um fim socioeconômico. $\mathbb{E}$ somente na medida em que é este meio para um fim é que possui algum valor. A tese de Bernal é tanto prescritiva quanto descritiva. Isto é, Bernal tanto defende que a ciência deve ser guiada por propósitos socioeconômicos, pela indústria, para a satisfação das demandas da sociedade, quanto defende que ela tem sido assim historicamente:

O "desenvolvimento progressivo da ciência advém da renovação contínua de sua interconexão com a indústria": a ciência soluciona problemas que surgem primariamente de questões práticas relacionadas a "necessidades econômicas", trazendo-nos receitas que descrevem como as coisas devem ser feitas e meios racionais para o planejamento consciente da produção e da ordem social. (NIINILUOTO. 2004, p. 289) ${ }^{13}$

Bernal, como o aponta Niiniluoto, é um crítico contundente da concepção de ciência proposta por físicos-filósofos como Heisenberg, Schrödinger e Cohen. No seu entendimento, a ciência está a serviço da sociedade, e a melhor maneira de servi-la é produzindo conhecimentos aplicáveis que possam gerar tecnologia e inovação, sendo industrializados, aumentando o grau de conforto e infraestrutura das sociedades, contribuindo para o bem-estar individual e social. Neste sentido, ciência não é a busca por conhecimento, mas o emprego do conhecimento na busca por progresso social. Bernal fala em "cura de doenças", "descobertas benéficas" e "transformação social" e condena a noção de ciência pura e sua "busca por Verdade". De acordo com Niiniluoto, a orientação do utilitarismo de Bernal é de cunho instrumentalista, isto é, a ciência deve ser um instrumento - deve ser instrumentalizada - para servir a propósitos socialmente úteis, com finalidades práticas:

A concepção de ciência de Bernal é instrumental, a ciência é instrumentalmente orientada na medida em que considera os valores epistêmicos como meios para fins que pertencem à esfera das aplicações sociais do conhecimento científico - e rejeita explicitamente a ideia de que a verdade pode ser valiosa por si mesma. (NIINILUOTO. 2004, p. 291) ) $^{14}$

O que nos parece intrigante e irônico no pensamento de $\mathbb{J}$. $\mathbb{D}$. Bernal é que sua concepção marxista - sua prescrição marxista - da ciência serve perfeitamente bem para descrever o "estado da arte" da ciência em um mundo capitalista, dominado pelas relações de mercado, pela precificação do conhecimento, pela comoditização da ciência, pela importação do ethos gerencial pela universidade. A concretização do ideal de Bernal não ocorre em um mundo socialmente justo, economicamente igualitário, politicamente

\footnotetext{
${ }^{12}$ Tbidem, p. 31.

${ }^{13}$ Op. Cit.

${ }^{14}$ Ibidem.
} 
nobre, e nem o favorece ${ }^{15}$. Niiniluoto destaca que a imagem da ciência pensada por Bernal encontra-se superada pelo avançar dos tempos ${ }^{16}$. já não nos é mais possível aquela fé irrestrita no progresso social por meio da ciência. Defender a ciência em nada se confunde com ser cientificista:

Atualmente, o otimismo baconiano de Bernal e a retórica marxista já estão ulltrapassados. Nós conhecemos demasiados males, a opressão e os retrocessos que nos tem chegado sob os nomes de ciência e tecnologia. Aindla assim, admiro a coragem das concepções e esperanças de Bernal. (NIINILUTOTO. 2004, p. 290) ${ }^{17}$

A crítica que Niiniluoto faz do otimismo de Bernal nos faz lembrar o argumento de Schrödinger à concepção utilitarista da ciência: Não temos garantias de que o mero progresso científico tecnológico promoverá a felicidade que tanto almejamos, fazendo da sociedade aquele lugar ídílico tão sonhado:

(...) considero que é extremamente duvidoso saber se a felicidade da raca humana tem sido melhorada graças às evoluções técnicas e industriais que se seguiram ao rápido desenvolvimento da ciência natural (SCHRO̊DINGER. 1996, p. $98)^{18}$.

Schrödinger traça uma forte distinção entre atitude científica e cientificismo. É a ideologia cientificista, e não a ciência, que acredita no progresso auspicioso da humanidade por meio de um culto ao desenvolvimento tecnocientífico. Niiniluoto também discorda de Bernal em alguns pontos: não possui aquela fé demasiado otimista que relaciona ciência e justiça social, embora de modo algum descarte que, entre tropeços e desencontros, a ciência tem realmente contribuído de modo efetivo para a melhoria da qualidade de vida em todo o mundo. Além disso, Niiniluoto pensa que a ciência possui, além de seu valor instrumental, um valor cultural e que seus valores epistêmicos não são secundários e periféricos, mas primordiais e centrais. O filósofo finlandês salienta a dicotomia entre a busca epistêmica pela compreensão da realidade, expressa pelo cognitivismo de Cohen, e a orientação instrumentalista da ciência industrial, representada pelo instrumentalismo de Bernal:

(...) ao passo que um cognitivista considera valiosa e racional a busca por uma ciência básica "pura", ou "pesquisa fuindamental teoricamente orientada", mesmo que o conhecimento obtido nunca nos leve a aplicações de utilidade prática, uim instrumentalista justifica a racionalidade de toda atividade científica com algum tipo de pesquisa aplicada ou estratégica. Esta é uma das razões pelas quais eu prefiro um cognitivismo socialmente responsável ao tipo de instrumentalismo representado por Bernal. (NIINILUOTO. 2004, p. 292) ${ }^{19}$

\footnotetext{
${ }^{15}$ Uma leitura das correspondências de Marx e Engels ilustra muito bem como os interesses científicos destes autores eram diversificados e amplos, abarcando grandes problemas teóricos, não se reduzindo a aspectos práticos e utilitários. Ver: ENGELS, Friedrich. Cartas sobre las ciencias de la natureza y las matematicas. Barcelona: Anagrama, 1975. No prefácio de Dialética da natureza, Engels reconta a história das ciências da natureza, enfatizando não somente sua importância prática, mas, sobretudo, seu teor revolucionário, teórico, como elemento de transformação de nossa compreensão do universo. Ver: ENGELS, Friedrich. Dialética da natureza Rio de Janeiro: Paz e terra, 3a ed, 1979. Podemos lembrar que o próprio Marx se interessava profundamente pelas ciências da natureza não somente por seu papel no aumento das forcas produtivas, mas pelas questões filosóficas que lhe são próprias. Ver: FEIJó, Ricardo Luis C. A ideia de ciência em Marx. Política \& Sociedade - Florianópolis - Vol. 14 - № 31 - Set./Dez. de 2015, pp. 293-325. p. 310. A concepç̃o marxista de ciências da natureza está, muito claramente, preocupada com questões teóricas de ontologia e epistemologia, e não somente com problemas práticos. O que se disputa, de um modo geral, é uma determinada concepção de mundo. Para uma visão geral acerca de tal característica, recomendamos: FREIRE JR., Olival. Ciência e filosofia na experiência socialista. Princípios, 21, 1991, p. 70-78.

${ }^{16}$ Não é nossa intenção aqui problematizar se a visão marxista de ciência e sociedade encontra-se ultrapassada, ou quão atual deve ser considerada.

${ }^{17}$ Op. Cit.

${ }^{18}$ SCHRÖDINGER, Erwin. A Natureza e os Gregos seguido de Ciência e Humanismo. Lisboa: Ediçốes 70, 1996. ${ }^{19}$ Ibidem.
} 
Na axiologia da pesquisa científica do cognitivismo socialmente responsável de Niiniluoto, os valores epistêmicos intrínsecos, tais como "conhecimento" e "verdade" ocupam uma posição fundamental, mas os valores sociais também são contemplados. 0 que Niiniluoto faz é se perguntar. "Qual a melhor maneira de se alcançar sucessos práticos e avanços sociais por meio da ciência?". Sua resposta parece ser a de que quanto mais fizermos bem feito, ciência como um fim em si mesmo, mais criaremos as bases epistêmicas necessárias ao desenvolvimento social.

Outra razão em preferir o cognitivismo é baseada sobre a observação de que $o$ sucesso empírico e pragmático da ciência pode ser explicado por seú sucesso epistêmico - e não o contrário, como sugere Bernal. Mesmo se você valoriza mais as aplicações práticas da ciência do que seus avanços puramente epistêmicos, o modo mais efetivo de alcançá-las é por meio do desenvolvimento de teorias poderosas. "A teoria é a coisa mais prática que pode sei concebida" como sustentou Ludwig Boltzmann (Boltzmann 1974, p. 35). Assim sendo, ao invés de ser uma ideologia perigosa e reacionária, como defende Bernal, a busca por valores epistêmicos intrínsecos é um elemento explicativo e indispensável à garantia de que a ciência é capaz de servir como fonte de valores culturais na sociedade. [grifo nosso] (NIINILUOTO. 2004, p. 292-293) ${ }^{20}$

Argumentamos que a concepção epistêmica ${ }^{21}$ socialmente robusta sustentadla por Niiniluoto pode nos ajudar a compreender a situação da ciência contemporânea no mundo globalizado em que Estados e corporações desempenham em conjunto a função de atores globais que determinam as regras do jogo: tudo deve ser comoditizado, mercadorizado pela indústria ou negociado no mercado financeiro.

O século passado registrou um processo de acentuada transição na axiologia da pesquisa científica de um ethos acadêmico para um ethos gerencial (ZIMAN, apud REIS, $2010)^{22}$. A pesquisa científica tornou-se cada vez mais instrumental: importante e bem remunerada tão somente porque estratégica para o desenvolvimento das indústrias bélica, farmacêutica, agroquímica, de energia, etc. O Estado, por sua vez, se relaciona com a ciência reproduzindo o modelo corporativo: fomenta a ciência condicionando-a a uma política de metas, produtivista e gerencial, para que dela possa extrair os recursos necessários para o incremento do PIB. Conforme Mendonça e Camargo Jr. (2011,2012), o processo de comoditização da ciência planifica o mundo e, quiçá, desfigura a ciência de modo irreversível ${ }^{23}$.

Todavia, compreendemos que tal processo se iniciou bem antes do século XX. Tanto na Alemanha de Schelling (1775-1854) quanto na Inglaterra de Willian Whewell

\footnotetext{
${ }^{20}$ Ibidem.

${ }^{21} \mathrm{O}$ termo "concepção epistêmica" nos parece mais adequado. Ora, tal concepção é justamente aquela que defende que os valores epistêmicos são valores intrínsecos. Já o termo cognitivismo, de cognição, pode ser bastante ambíguo. Embora o termo "valores cognitivos" seja usado por vários autores na área de filosofia da ciência, como Hugh Lacey, é importante destacar que "cognição" e "cognitivo" são conceitos que pertencem ao jargão da psicologia e designam a capacidade ou o processo de aprendizagem. Neste sentido, uma teoria de física é tão cognitiva quanto uma ciranda de roda, pois ambos são frutos do processo cognitivo humano. A ciência não é mais ou menos cognitiva do que nenhuma atividade humana organizada. Ademais, o termo cognitivismo designa uma concepção teórica que ganhou força na psicologia a partir dos anos 1950. Os cognitivistas criticavam os behavioristas porque ignoravam a função da cognição. Já o termo "epistêmico" possui uma longa tradição e denota não somente aquilo que é da esfera da aprendizagem, mas aquilo que se trata de conhecimento científico. Todavia, para sermos fiéis ao texto original, feitas nossas ressalvas, permaneceremos utilizando o termo cognitivismo como designando a teoria de acordo com a qual os valores epistêmicos são fundamentais para a axiologia da pesquisa científica.

${ }^{22}$ REIS, Verusca Moss, S. O Problema do Ethos Científico no Novo Modo de Produção da Ciência Contemporânea. Rio de Janeiro: Universidade do Estado do Rio de Janeiro (Tese de Doutorado), 2010.

${ }^{23}(2011)$ : MENDONÇA, André Luís de Oliveira; CAMARGO JR, Kenneth Rochel. O complexo médico-industrial no contexto da comoditização da ciência: relativizando o relativismo. Revista Brasileira de Ciência, Tecnologia e Sociedade, Vol. 2, No 2, p.7-31. (2011). (2012): MENDONCA, André Luis Oliveira; CAMARGO JR, Kenneth Rochel. Complexo médico-industrial/financeiro: os lados epistemológico e axiológico da balança. Physis, Rio de Janeiro, v. 22, n. 1, p. 215-238, 2012.
} 
(1798-1866), o enfraquecimento da pesquisa desinteressada e do espírito especulativo puro nas universidades, o enfraquecimento das universidades enquanto centros de livre criação intelectual e de cultivo do conhecimento como fim em si mesmo, foi diagnosticado por estes pensadores. Em seu A formação pela ciência: Schelling e a ideia de universidade ${ }^{24}$, Ricardo Barbosa lembra que o filósofo alemão rejeitava a ideia de que a universidade deveria ser um centro de formação profissional, cujo principal objetivo seria o de capacitar e qualificar mão de obra para o mercado de trabalho (BARBOSA. 2010 , p. 87). Schelling valorizava a produção (intelectual) criativa e não o utilitarismo. Sua preocupação revela que já naquela época a universidade alemã engendrava a dicotomia entre a busca epistêmica por compreensão da realidade e a orientação instrumentalista de uma ciência voltada para as demandas socioeconômicas:

Esta exigência do estudo acadêmico - aprender para produzir criativamente contrasta com toda visão meramente utilitária da ciência. Schelling se refere ao "nome repugnante" que se deu às ciências voltadas para a satisfação das necessidades humanas iimediatas: as "ciências-ganha-pão", Brotwissenschaften. Nenhuma ciência mereceria esse nome. (BARBOSA. 2010, p. 92) $)^{25}$

Em A ciência como vocação, Weber retrataria a americanização e a empresalização da universidade alemã no início do século $\mathrm{XX}^{26}$. No caso de Whewell, Leonardo Rogério Miguel destaca que o cientista britânico se interessava pelas relações entre ciência e sociedade e nutria certa preocupação com a profissionalização da ciência que se processava em sua época:

Whewell estava ciente dessa transição e, diante disso, elaborou seu projeto tendo em vista a formação de futuros investigadores capazes de evitar as tendências utilitarista, instrumental e especializada de produção de conhecimento e tecnologia İgrifo nosso] (MIGUEL. 2012, p. 21)

Podemos notar, portanto, que, em meados do século XIX, Whewell já percebera a pressão exercida pela tendência utilitarista e instrumentalista na comunidade científica, o que era fonte de preocupação, uma vez que a ciência, para Whewell, era uma atividade que deveria ser socialmente responsável, mas sem se esquecer de ser, antes de tudo, uma busca pelo saber:

Afinal, antes de ser um meio para o progresso material da sociedade, a ciência, para Whewell era uma empreitada vocacional, de caráter espiritual, que implicaria o engajamento e a responsabilidade do praticante em relação a determinados valores sociais. [grifo nosso] (MIGUEL. 2012, p. 21) ) $^{28}$

Mais tarde, na França, Pierre Duhem (1861-1916) em sua A teoria física ${ }^{29}$ demonstrava sua preocupação com o avanço da mentalidade industrial na física inglesa. De acordo com Duhem, a física na Inglaterra havia se juntado "às exigências da indústria", estando condicionada pelas pressões práticas do mercado e difundindo entre a população a confusão entre ciência e tecnologia. De acordo com Duhem, a universidade inglesa havia sido invadida pelo utilitarismo:

\footnotetext{
${ }^{24}$ BARBOSA, Ricardo. A Formação pela Ciência: Schelling e a ideia de universidade. Rio de Janeiro: Eduerj, 2010 ${ }^{25}$ Idem.

${ }^{26}$ WEBER, Max. A ciência como vocação. Arthur Morão (Trad.). Lusofia [on line], p. 4. Disponívell em: $<<$ www.lusosofia.net/textos/weber a ciencia como vocacao.pdif $>>$

${ }^{27}$ MIGUEL, L. R. Willam Whewell: as motivações e os objetivos de um filosofo da ciência in Perspectivas contemporâneas em Filosofia da Ciência. Antonio Augusto Passos Videira (Org.). Rio de Janeiro: Eduerj, 2012 ${ }^{28}$ Tbidem.

${ }^{29}$ DUHEM, Pierre. A Teoria Física: Seu objeto e sua estrutura. Tradução Rogério Soares da Costa. Rio de Janeiro: Eduerj, 2014.
} 
O ensino superior já se contaminou pelo utilitarismo e o ensino secundário é presa da epidemia. Eim nome do utilitarismo, faz-se tabula rasa dos métodos que até aqui haviam servido para expor as ciências físicas. Rejeitam-se as teorias abstratas e dedutivas. Esforça-se por abriir aos alunos caminhos indutivos e concretos. Não se pretende mais dar aos jovens espíritos ideais e princípios, mas números e fatos. (DUHEM. 2014, p. 125-126) ${ }^{30}$.

Duhem chama a atenção para a desfiguração utilitarista dos valores da ciência. Ontem e hoje sabemos que a ciência possui valores, e que se são substituídos por outros, a direção da pesquisa científica se modifica. O geneticista brasileiro Newton Freire-Maia, em A ciência por dentro ${ }^{31}$, ressalta a ciência como parte da cultura, um conjunto de práticas sociais com nuances políticas inegáveis. Conforme Freire-Maia, a ciência não é neutra:

Há quem defensa a tese da neutralidade da ciência, achando que o bom ou mau uso que dela se faz depende de decisões de não-cientistas (políticos, militares, empresários, etc.) que se apropriam de seus resultados e os aplicam de acordo com seus interesses. Não se pode negar, no entanto, que há uma parte da ciência que se encontra a serviço de não-cientistas, com objetivos preestabelecidos de luicro, dominação e guerra. Os cientistas que executam essa ciência programada colocam-na deliberadamente a serviço de outra instância decisória, revelando que essa ciência não possui a inocência e a pureza que alguns nela querem ver (FREIRE-MAIA. 1991, P. 129)

Ainda hoje a tese da neutralidade pode ser defendida por epistemólogos tradicionais e cientistas pouco versados na história de sua própria atividade. No entanto, estamos vendo o quão antiga é a preocupação com a degradação dos valores científicos a partir das pressões exercidas por interesses muitas vezes contrários ao bem público e à pesquisa não utilitária. A ciência é parte da sociedade; parte em constante interação com o todo:

A ciência representa um corpo de doutrinas gerado ou em geração num meio social específico e, obviamente, sofrendo as influências dos fatores que compõem a cultura de que faz parte. Produto da sociedade, influi nele e dela sofre as inffluências (FREIRE-MAIA. 1991, p. 128)

Para o geneticista brasileiro, a natureza complexa da ciência faz dela alvo de múlitiplos interesses conflitantes, donde concluímos que determinadas tensões sejam inevitáveis. Freire-Maia responde à questão central desse trabalho - qual é o valor da ciência? - lembrando que existem, ao menos, duas forças motrizes que atuam paralelamente: o amor à ciência move a pesquisa fundamental, o interesse utilitário impulsiona a tecnologia:

Em geral, faz-se ciência por dois motivos: curiosidade intelectual e interesses em fins utilitários. O primeiro decorre do que se poderia chamar de "amor à ciência" e gera, como seu produto primeiro, o prazer de executar as tarefas de investigação científica. O "verdadeiro" cientista tem uma imensa satisfação em

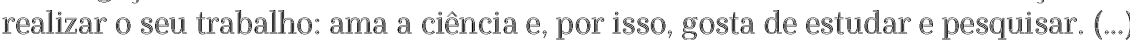
O amor à ciência, a curiosidade intelectual e o gosto do trabalho representam fatores imbricantes que movem a realizacão da ciência básica (erroneamente chamada, por alguns, de ciência pura), que, como vimos, pode ou não gerar

\footnotetext{
${ }^{30}$ Idem.

${ }^{31}$ FREIRE-MAIA, Newton. A ciência por dentro. Petrópolis, RJ: Vozes, 1991.

${ }^{32}$ Idem.

${ }^{33}$ Tbidem.
} 
aplicações. O interesse em fins utilitários move a realização da ciência aplicada (tecnologia) (FREIRE-MAIA. 1991, p. 128) ${ }^{34}$.

A tecnologia é desejável, mas não pode ser a finalidade da ciêncỉa. Para FreireMaia, o cientista năo deve confundir os interesses científicos com os interesses financeiros de empresários e políticos. Para tanto, é necessário ter "vocação para a ciência", um espírito tenaz e "religioso" e um determinado caráter, um ethos. Muito além do CUDOS $^{35}$ de Merton, Freire-Maia pensa em um perfil do cientista, chegando a uma lista com 18 itens ${ }^{36}$, dentre os quais destacamos amor e dedicação à pesquisa, honestidade, espírito crítico, preocupação com seu papel na sociedade e com os efeitos de seu trabalho, e determinadas formas de desinteresse ${ }^{37}$. 0 "desinteresse" não pode ser irrestrito, primeiro porque seria irrealizável, segundo porque nem todo desinteresse é bem-vindo. Para o geneticista o cientista deve estar interessado em obter reconhecimento e prestígio entre os pares, mas deve ser desinteressado quanto ao público leigo, isto é, não deve ser movido por desejo de popularidade.

O cientista deve possuir desinteresse por outras atividades que sejam conflitantes com a tarefa do pesquisador ${ }^{38}$. Se combinarmos essa regra com aquela que diz que o cientista deve preocupar-se com seu papel social e com as consequências de seu trabalho, veremos que se a sociologia, a história, os novos estudos sociais e conceituais de ciência nos revelam que a ciência não é neutra, como Freire-Maia já o dizia, a axiologia da pesquisa científica nos diz que o cientista, o sujeito da pesquisa científica, deve possuir um código de ética, um determinado conjunto de valores, ou seja, que ele não deve ser neutro. A neutralidade, no caso individual, não é isenção de responsabilidade, é omissăo, logo, confissão de irresponsabilidade. Neutralidade, em último caso, seria adesão ao status quo, afinal, Qui tacet, consentire videtur, "quem cala, consente ${ }^{239}$. O físico da Universidade de Yale, Samuel MacDowell, defende semelhante posição em Responsabilidade social dos cientistas:

Em virtude da ligação cada vez maior entre progresso científico e desenvolvimento social, cabe aos cientistas indagar com mais frequência e de modo mais crítico e sistemático sobre a uitilização da ciência e dos resultados de suas pesquisas. Creio que há eviidência contundente em favor do argumento de que os investimentos públicos em pesquisa científica têm tido um retomo

\footnotetext{
${ }^{34} \mathrm{Idem}$.

${ }^{35}$ Conforme Reis (2010), o ethos mertoniano é formado pelas seguintes normas: Comunalismo (A ciência deve ser propriedade comum da sociedade), Universalismo (Sua linguagem e procedimentos devem ser abertos e universais e não restritos e particullares), Desinteresse (Os cientistas não devem ser movidos a interesses financeiros, políticos etc; ou seja, interesses "não epistêmicos"), Ceticismo Organizado (A ciência deve ser autocrítica e o critério de escollha e rejeição de teorias deve ser estritamente epistêmico). No entanto, o ethos vigente seria pós-acadêmico (Cf. Ziman) ou não mertoniano, predominando PLACE ao invés de CUDOS. PLACE significaria Propietário (ao invés de comum), Local (ao invés de universal), Autoritário (portanto não democrático), Comissionado (Ao invés de desinteressado) e Especializado. Para saber mais, ver: REIS, Verusca Moss Simões dos; VIDEIRA, Antonio Augusto Passos. John Ziman e a ciência pós-acadêmica: consensibilidade, consensualidade e confiabilidade. Sci. stud., São Paulo, v. 11, n. 3, p. 583-611, 2013

${ }^{36}$ (1) amor e dedicação à pesquisa, (2) honestidade, (3) inteligância, (4) imaginação, (5) curiosidade, (6) organização (disciplina), (7) capacidade de trabalho, (8) interesse pelo estudo (leituras científicas), (9) espírito crítico, (10) espírito aberto a novidades, (11) preocupação com seu papel na sociedade e com os efeitos de seu trabalho, (12) poder de concentraç̃o, (13) rapidez no trabalho, (14) capacidade para traballhar em equipe, (15) capacidade de redação, (16) desinteresse por outras atividades que sejam conflitantes com a tarefa do pesquisador, (17) desejo de reconhecimento e prestígio no meio científico internacional, (18) desinteresse por popularidade no meio leigo.

${ }^{37}$ Op. Cit. p, 180.

${ }^{38} \mathrm{Idem}$.

${ }^{39}$ Se nós, que fazemos estudos de ciência, pretendemos que estes sejam científicos, temos de admitir que também em nosso trabalho não há neutralidade, e, portanto, não há "descrição pura" da ciência "tall como é". Toda descrição carrega consigo uma carga de valores, de metafísica, axiologia, ideologia, de visão política e social, logo, toda descrição possui um viés normativo, ainda que tácito. O mito da neutralidade apenas nos obnubla a compreensão de que a vindicação de uma "descrição pura" já é, por si mesma, uma adesão ao status quo.
} 
bastante compensador em termos da utilização para o bem-estar social dos progressos científicos obtidos. Por outro lado, creio também que se pode questionar, não somente quanto à aplicação de conhecimentos científicos com finalidades destrutivas ou nocivas à humanidade e à natureza, mas também quanto à distribuição destes benefícios entre diferentes setores da sociedade. Considerarei aqui, em particular, quatro aspectos do relacionamento da ciência com a sociedade que, a meu ver, requerem a atenção e a reflexão do cientista: 1) Aplicação da ciência com fỉns militares; 2) Impacto do avanço tecnológico e industrial no meio ambiente; 3) Distribuição dos benefícios resultantes do progresso científico e tecnológico; 4) Difusão da ciência e o problema da educação (MACDOWELL. 1988 , p. 70$)^{40}$.

MacDowell enfatiza que o cientista não pode se alienar, voluntariamente, de seu traballho. Ao declarar que não tem responsabilidade sobre os usos, impactos e consequências de sua pesquisa, o pesquisador promove sua despolitização e endossa o mito da neutralidade. Parece ser justamente essa a postura de Gleiser em O papel do Estado e dos cientistas em projetos de produção de armas ${ }^{41}$, ao defender que a ciência não é moral nem imoral, mas amoral, uma coletânea de fatos e observações, portanto, neutra ${ }^{42}$. Os cientistas projetam as armas, mas são os políticos que decidem usá-las. Tal posição é oposta àquela de homens de ciência como Macdowell, que, ao contrário de Gleiser, pensa que é preciso que o cientista assuma criticamente a responsabilidade moral que lhe compete, lutando para que a ciência sirva aos interesses sociais do bem público. Macdowell cita quatro eixos principais que merecem atenção dos pesquisadores. (1) Acerca das aplicações militares da ciência, o físico lembra que, desde a fabricação das primeiras armas nucleares, o arsenal mundial aumentou assustadoramente. Os cientistas, a seu ver, não podem desvincular seu trabalho da política e, portanto, deveriam se posicionar aberta e radicalmente contrários aos usos militares da pesquisa científica. Quase trinta anos após o artigo de MacDowell podemos constatar que a situação só piorou; (2) O segundo ponto listado tratava dos impactos ambientais do avanço tecnológico. O físico relatava os imensos perigos do lixo radioativo oriundo da geração de energia por matriz nuclear e apontava para a crescente degradação do meio ambiente por poluição de todo o ecossistema a partir do crescimento industrial e do agronegócio; (3) A má distribuição dos progressos científicos e (4) a falta de educação de qualidade para a maior parte da população, sobretudo nos países em desenvolvimento, também são desafios diante dos quais o cientista não deve silenciar.

Podemos notar que ao longo do século XX diversos cientistas demonstraram uma grave preocupação com um fenômeno que poderíamos chamar de "comoditização da ciência", que seria a completa apropriação utilitarista da pesquisa científica pelos interesses financeiros e políticos do capital. O capital, por meio de corporações e Estados, não busca nem a verdade e nem o bem público, mas tão somente o lucro e o poder. Tal fenômeno promoveria mudanças drásticas no ethos das ciências, impactando profundamente suas práticas. A pesquisa científica, plenamente convertida em Big

\footnotetext{
${ }^{40}$ MACDOWELL, Samuel. Responsabilidade social dos cientistas: natureza das ciências exatas. Estud. Av., São Paullo, v. 2, n. 3, p. 67-76, Dec. 1988.

${ }^{41}$ GLEISER, Marcelo. O papel do Estado e dos cientistas em projetos de produção de armas. Folha de São Paulo, 15 de Abril de 2017.

${ }^{42}$ Para uma posição francamente oposta à de Gleiser, podemos lembrar o texto de Marcuse, $A$ responsabilidade do cientista: "A proposição que desejo apresentar é a seguinte: a ciência (isto é, o cientista) é responsável pelo uso que a sociedade faz da ciência; o cientista é responsável pelas consequências sociais da ciência. Argumentarei que esta proposiç̃̃o não depende para sua validade de quaisquer normas morais fora e além da ciência, ou de qualquer ponto de vista religioso ou humanitário. Em vez disso, sugiro que a proposição é ditada pela estrutura interna e o telos da ciência, e pelo lugar e função da ciência na realidade social". MARCUSE, Herbert. A responsabilidade da ciência. Sci. stud, São Paulo, v.. 7, n. 1, p. 159-164, Mar. 2009. p.159. E ainda: (...) a pretensa neutralidade da ciência e a indiferença quanto aos valores, das quais ela se gaba, na verdade promovem o poder de forças extemas sobre o desenvolvimento científico interno (p.161). MARCUSE, $H$. The responsibility of science In: KRIEGER. L. \& STERN, F. (Org.). The responsibility of power: historical essays in honor of Hajo Holborn. New York: Doubleday, 1967. p. 439-44.
} 
Science e tecnociência aprofundaria crises. O desenvolvimento da indústria bélica, por exemplo, colocou o mundo em outro patamar de risco ao longo do século passado. Dormimos todas as noites sobre centenas e centenas de ogivas nucleares. A possibilidade de uma distopia tecnocapitalista utilitarista surge em nosso horizonte de eventos como um novo mundo nada admirável.

Justo em época tão conturbada a filosofia quer abdicar voluntariamente do esforço tenaz por oferecer vuma força de orientação e unificação do mundo? " $E$ muito!", dizem alguns. "Arrogância e devaneio!" repetem outros. Ao fundo, o coro repete incessantemente que não cabe ao filósofo dizer como as coisas devem ser, que a filosofia deve despir-se de suas ilusões utópicas e de sua mania de grandeza. A filosofia deve contentar-se em descrever o mundo, jamais pensar em transformá-lo. Na aurora do sécullo XXI a filosofia deve ser mera expectadora, mera observadora da realidade social. Logo em uma época em que todos são atores sociais, os filósofos não podem prescrever como as coisas poderiam ser, mas apenas observar e catalogar os fatos "tais como são". Mas isso realmente ainda seria filosofia? Sobretudo nos momentos de crise que o valor da filosofia pode se revelar de modo mais contundente. Diante da transformação do ethos científico e do avanço do utilitarismo, Ilkka Niiniluoto não se limitou a descrever a paisagem atual, mas apontou novos caminhos. Sua defesa de um cognitivismo socialmente responsável como parte do valor cultural da ciência é um manifesto claro em defesa dos valores epistêmicos que não podem ser esmagados pelas engrenagens utilitárias daqueles que não pensam a ciência como um fim em si mesmo, nem os seus resultados como caminhos para a promoção da prosperidade comum e da justiça social, mas somente como uma ferramenta, um instrumento, para a satisfação de seus interesses particulares.

Não basta que a ciência produza tecnologia, os cientistas devem se posicionar: quais tecnologias, com que interesses e impactos, estendidas a quantos por cento da população? Ciência e tecnologia para quem? E produzir tecnologia, basta? Antonio Augusto Passos Videira, em seu artigo Metafísica, físicos, valores: Um ensaio sobre a crise dos fundamentos das ciências naturais na passagem do século XIX para o século $X X^{43}$, nos lembra que a questão acerca do valor da ciência permanece fulcral, e que os cientistas respondem negativamente esta última questão:

Os cientistas sabem que não se pode determinar o valor da ciência somente porque a ciência é capaz de criar produtos tecnológicos. A ciência deve possuir um valor intrínseco, muitas vezes associado ao fato de ser um tipo específico de conhecimento. Ela não se resume aos produtos que gera. (VIDEIRA. 2011, p. 193)

Nos séculos XIX, XX e XXI cientistas de diversas partes do mundo pontuaram que a ciência pressupõe valores que se corrompidos poderiam colocar em risco sua própria existência. Claro que cada qual falou a partir de um lugar, de um contexto social e histórico peculiar, e todas essas dimensões devem ser levadas em conta. No entanto, com palavras diferentes, disseram que o valor da ciência não se reduz à aplicação, que seu valor não é utilitário, que a utilidade desejável decorre como consequência. Podem todos estar errados. Mas os fatos, a situação do mundo atual, a preocupação de cientistas de nossos tempos, parecem indicar que não.

\section{Considerações finais}

- que Niiniluoto chama de cognitivismo socialmente responsável nós concebemos como uma concepção de ciência "epistemicamente centrada, politicamente ativa e socialmente robusta", que busque a verdade, lute pelo bem comum, e contribua com a criação de formas cada vez mais belas e criativas de vida e organização social. A

${ }^{43}$ VIDEIRA, Antonio Augusto Passos. Metafísica, Físicos, Valores: Um ensaio sobre a crise dos fundamentos das ciências naturais na passagem do século XIX para o século XX. Ensaios Filosóficos, Volume IV - outubro/2011 
filosofia pode e deve participar do debate público sobre o valor da ciência, e assim como Leite Lopes, deve se perguntar "Que ciência e que cultura, para qual projeto de sociedade e em qual mundo?"44, que ciência, servindo a quais interesses?

Pensar qual é o valor da ciência parece ser hoje tão urgente e necessário quanto fora outrora. Como cientificistas podemos apenas nos alienar e iludir, e pensar de modo cândido que tudo vai bem, que a ciência está prosperando e o mundo é um lugar maravilhoso. Mas esse conto de fadas não resiste ao menor escrutínio crítico. O utilitarismo, que faz da pesquisa científica um mero instrumento para a promoção dos interesses estratégicos da plutocracia das grandes corporações e dos Estados mais ricos corrompe o ethos científico e ameaça tanto a ciência quanto a sociedade. Se, como filósofos, pretendemos encarnar o mito da neutralidade e insistir que não podemos e nem devemos dizer como a ciência deve ser, mas apenas descrever como a ciência é, o que estaremos fazendo é assumir que não há cientificidade na fillosofia da ciência. Ora, se a ciência não é neutra, e se nós somos neutros, logo, o que fazemos, não possui valor científico. Se nem o jornalismo se resume a descrever os fatos, por que esse papel caberia a nós? Além disso, a atividade exclusivamente descritiva pode ser analítica, mas não é crítica. A mera descrição, ao não ser crítica, deixa de ser filosófica. A filosofia da ciência deve vencer o seu acanhamento letárgico que a dominou nos últimos anos e oferecer respostas críticas e positivas para essa questão que não se esgota. Qual é o valor da ciência?

Defendemos que o valor da ciência não pode ser apenas utilitário, econômico, social e político. Evidentemente todas essas dimensões fazem parte da pesquisa científica. Mas além de tais aspectos concretos, mensuráveis e instrumentais, a ciência possui um valor intangível que é intelectual, cultural, enfim, filosófico. Por meio dela criamos cosmovisões, construímos concepções de mundo, imagens de natureza, sondamos a beleza e o mistério do cosmos. Uma pesquisa não precisa de outras justificativas, a não ser essas, para ser considerada de fundamental importância. A imagem de ciência que propomos é de uma pesquisa epistemicamente centrada, socialmente robusta e politicamente engajada ${ }^{45}$. A ciência deve buscar a verdade ${ }^{46}$, promover o bem-estar social, o bem comum, e criar e contemplar o belo. Pensamos que tal imagem crítica e propositiva de ciência seja compatível com o cognitivismo socialmente responsável de Ilka Niiniluoto, oferecendo, portanto, uma alternativa para superarmos a dicotomia entre uma concepção epistêmica e o reducionismo utilitarista. O filósofo pode tomar uma posição entre o epistemicismo e o utilitarismo. Por que restringir-se à descrição dos fatos quando é a reflexão sobre os valores que se impõe com urgência em nossos tempos? Não é hora de ficarmos imóveis. Afinal, não é ao anoitecer que a "Ave de Minerva" alça seu voo?

\section{Referências}

\footnotetext{
${ }^{44}$ LOPES, J. L. A ciência e a construção da sociedade na América Latina In Ciência e Liberdade. Rio de Janeiro: Editora UFRJ; CBPF/MCT, 1998. p. 166

${ }^{45}$ Tal imagem poderia ser acusada de cândida, como se pensasse a ciência como uma Torre de Marfim. Tal crítica é vã̃ por duas razões. Primeiro, porque nossa concepç̃o não é somente epistemicamente centrada. É também socialmente robusta, o que significa que assumimos as dimensões histórica, social, institucional e política da ciência. Segundo, porque ao dizermos como a ciência deve ser não nos descuidamos de como ela é. Um ideal só possui valor se não concorda com os fatos, e se para ser alcançado algo de diferente deve ser feito. Ao apresentarmos nossa imagem de ciência, estamos dizendo qual é o ideal que consideramos que deve impulsioná-la.

${ }^{46} \mathrm{O}$ que é a verdade? A teoria científica é uma explicação da realidade tall como ela é ou uma representação verossímil? Não poderemos desenvolver tais tópicos nesta ocasião, mas nos interessa pontuar que nossa visão se alinha com a de Max Planck, para quem a ciência deve buscar uma compreensăo do Absoluto, isto é, o entendimento pleno do real, mas que isto é a meta da ciência, o seu ideal, aquilo que a anima e a impulsiona, de modo que é necessário reconhecer que as teorias científicas jamais alcançam esse Absoluto, que apenas elaboram imagens da natureza mais "próximas" do real. Para mais, ver a Autobiografia cientifica de Planck.
} 
BARBOSA, Ricardo. A Formação pela Ciência: Schelling e a ideia de universidade. Rio de Janeiro: Eduerj, 2010.

BERNAL, John D. The Social Function of Science. London: George Routledge \& Sons LTD., 1946.

BOHR, Niels. Física atômica e conhecimento humano. Vera Ribeiro (Trad.). Rio de Janeiro: Contraponto, 1995.

BOLTZMANN, Ludwig. Escritos Populares. Tradução Antonio Augusto Passos Videira. São Leopoldo: Ed. da Unisinos, 2004.

BORN, M; AUGER; SCHRÖDINGER, E; HEISENBERG, W. Problemas da Física Moderna. Trad. Gita. K. Guinsburg. São Paulo: Perspectiva: 2006.

BRONOWSKI, J. Ciência e Valores Humanos. Alceu Letal (Trad.) São Paulo: Editora da Universidade de São Paulo, 1979.

CHARPACK, G; OMNÈ, R. Ciência e Sociedade in Sejam sábios, tomem-se profetas. Rio de Janeiro: Editora Best Seller, 2007.

COHEN, Jonathan L. Knnowledge and Language. Selected essays. James Logue (Edt). Dordrecht: Kluwer Academic Publishers, 2002.

CUPANI, Alberto. A propósito do 'ethos' da ciência. Episteme, 3: 16-38 (1998).

CUPANI, Alberto. A tecnologia como problema filosófico: três enfoques. Sci. stud., São Paulo, v. 2, n. 4, p. 493-518, Dec. 2004.

DASTON, Lorraine; GALISON, Peter. Objectivity. New York: Zone Books, 2007.

DASTON, Lorraine; RICHARDS, JOAN.I. Bernard Cohen. Physics Today V.57, N.7, p.75 (2004)

DIÁZ, JOSÉ Antonio Acevedo. De La ciencia a La tecnociencia (II). La ciencia industrial e la Big Science. Disponível em: <http: //cooperacionib.org/índex.php>

DIÁZ, JOSÉ Antonio Acevedo. De La ciencia a La tecnociencia (III). $Y$, al final, tecnociencia. Disponível em: <http: //cooperacionib.org/índex.php>

DUHEM, Pierre. A Teoria Física: Seu objeto e sua estrutura. Tradução Rogério Soares da Costa. Rio de Janeiro: Eduerj, 2014.

EINSTEIN, Albert. Considerações Cosmológicas sobre a Teoria da Relatividade Geral In o Princípio da Relatividade. 3. ed. Tradução Mário José Saraiva. Porto: Fundação Calouste Gulbenkian, 1983.

EINSTEIN, Albert. Einstein Papers. Disponível em $<$ http://einsteinpapers.press.princeton.edu>.

EINSTEIN, Albert. Interview for American Institute of Physics. Disponível em: $<$ http://www.aip.org/history/mod/audio/fission/04einstein.html $>$.

ELIAS, Norbert. Mozart, sociologia de um gênio. Sérgio Goés de Paula (trad.). Rio de Janeiro: Jorge Zahar Ed., 1995.

ENGELS, Friedrich. Cartas sobre las ciencias de la natureza y las matematicas. Barcelona: Anagrama, 1975.

ENGELS, Friedrich. Dialética da natureza. Rio de Janeiro: Paz e terra, 3a ed, 1979.

FEIJÓ, Ricardo Luis C. A ideia de ciência em Marx. Política \& Sociedade - Florianópolis Vol. 14 - № 31 - Set/Dez. de 2015, pp. 293-325. p. 310. 
GALISON, $\mathbb{P}$. Culturas etéreas e culturas materiais. In A ciência tal qual se faz. Coord. Fernando Gil. Lisboa: Edições João Sá da Costa, 1999.

GALISON, P. Einstein's clocks, Poincaré's maps: empires of time. New York: W. W. Norton, 2004.

GALISON, Peter. Interview. Cambridge: Atomic Heritage Foundation, 2015. Disponível em: http://manhattanprojectvoices.org/oral-histories/peter-galisons-interview

GALISON, Peter. Os relógios de Einstein e os mapas de Poincaré. Lisboa: Gradiva, 2005.

GLEISER, Marcelo. O papel do Estado e dos cientistas em projetos de produção de armas. Folha de São Paulo, 15 de Abril de 2017.

GLERUP, C; HORST, M (2014) Mapping 'social responsibility' in science, Journal of Responsible Innovation, 1:1, 31-50.

HEISENBERG, Werner. A Imagem da Natureza na Física Moderna. Lisboa: Livros do Brasil, 1981.

A ordenação da realidade. Tradução de Marco Antônio Casanova. Rio de Janeiro: Forense Univiversitária, 2009.

A parte e o todo: encontros e conversas sobre física, filosofia, religião e política. Rio de Janeiro: Contraponto, 1996.

LACEY, Hugh. Existe uma distinção relevante entre valores cognitivos e sociais? Sci. stud., São Paulo, v. 1, n. 2, p. 121-149, June 2003.

LACEY, Hugh. Valores e Atividade Científica 1. São Paulo: Associação Filosófica Scientiæe Studia/Editora 34, 2008

LACEY, Hugh. Valores e Atividade Científica 2. São Paulo: Associação Filosófica Scientiæ Studia/Editora 34, 2010.

LOPES, José Leite. A ciência e a construção da sociedade na América Latina In Ciência e Liberdade. Rio de Janeiro: Editora UFRJ; CBPF/MCT, 1998. p. 166

MACDOWELL, Samuel. Responsabilidade social dos cientistas: natureza das ciências exatas. Estud. Av. São Paulo, v. 2, n. 3, p. 67-76, Dec. 1988.

MARCUSE, H. The responsibility of science. In: KRIEGER. L。 \& STERN, F. (Org.). The responsibility of power. historical essays in honor of Hajo Holborn. New York: Doubleday, 1967. p. 439-44.

MARCUSE, Herbert. A responsabilidade da ciência. Sci. stud., São Paulo, v. 7, n. 1, p. 159164, Mar. 2009. p.159.

MARX, Karl. Maquinaria e trabalho vivo - os efeitos da mecanização sobre o trabalhador in Manuscritos. Diego Grossi Pacheco (Trasc.). Disponível em: https://www.marxists.org/portugues/marx/1863/05/maquinaria.htm\#tr1

MENDONÇA, André de Oliveira. Dos Valores de Medida aos Valores como Medida: Uma avaliação axiológica da avaliação acadêmica. Ensaios Filosóficos, Volume X Dezembro/2014。 pp. 111-133

MENDONÇA, André Luís de Oliveira O. Por uma nova abordagem da interface ciência/sociedade: a tarefa da filosofia da ciência no contexto dos science studies. Rio de Janeiro: Universidade do Estado do Rio de Janeiro (Tese de doutorado), 2008.

MENDONÇA, André Luís de Oliveira. VIDEIRA, Antonio Augusto Passos.A representação como um processo coletivo tortuoso e custoso: Uma avaliação crítica da neomodernidade de Latour. Representaciones, $\mathrm{v} . \mathrm{VI}, \mathrm{n}$.1, 2010, p 75-91. 
MENDONÇA, André Luís de Oliveira; CAMARGO JR, Kenneth Rochel. O complexo médico-industrial no contexto da comoditização da ciência: relativizando o relativismo. Revista Brasileira de Ciência, Tecnologia e Sociedade, Vol. 2, No 2, p.7-31. (2011).

MENDONCA, André Luís de Oliveira; VIDEIRA, Antonio Augusto Passos. Progresso científico e incomensurabilidade em Thomas Kuhn. Sci. stud., São Paulo, v. 5, n. 2, p. 169183, jun. 2007.

MENDONCA, André Luis Oliveira; CAMARGO JR, Kenneth Rochel. Complexo médicoindustrial/financeiro: os lados epistemológico e axiológico da balança. Physis, Rio de Janeiro, v. 22, n. 1, p. 215-238, 2012.

MERTON, Robert K. The Normative Structure of Science, in Merton, Robert $\mathbb{K}$. The Sociology of Science: Theoretical and Empirical Investigations. Chicago: University of Chicago Press, 1973.

MIGUEL, Leonardo Rogério. Pensamento Científico, Integridade de Caráter e Coletividade: uma leitura sobre a ética da crença de William KKingdon Clifford. Dissertação de Mestrado. Rio de Janeiro: Universidade do Estado do Rio de Janeiro, 2011.

MIGUEL, Leonardo Rogério. R. Wiliam Whewell: as motivações e os objetivos de um filósofo da ciência in Perspectivas contemporâneas em Filosofia da Ciência. Antonio Augusto Passos Videira (Org.). Rio de Janeiro: Eduerj, 2012

NIINILUOTO, Ilka. Critical Scientific Realism. Oxford: Oxford University Press, 2004.

PLANCK, Max. Autobiografia científica e outros ensaios. Tradução Estela dos Santos Abreu. Rio de Janeiro: Contraponto, 2012.

PLANCK, Max. ¿Adonde va la ciencia? Felipe Jiménez de Asúa (Trad). 3a ed. Buenos Aires: Editorial Losada, 1947.

POINCARÉ, Henri. Ensaios Fundamentais. Vera Ribeiro (Trad.). Rio de Janeiro: Contraponto, 2008.

POINCARÉ, Henri. O Valor da Ciência. Helena Franco Martins (Trad.). Rio de Janeiro: Contraponto, 1995.

POINCARÉ. The Value of Science. New York: The Science Press. 1907.

POPPER, Karl. Três concepções sobre o entendimento humano in "Os Pensadores". Trad. Pablo Ruben Mariconda e Ruben de Almeida. São Paulo: Abril Cultural, 1980.

REIS, V. M. S. O Retorno ao Ethos Mertoniano na Ciência Pós-Acadêmica de John Ziman. Revista Brasileira de Ciência, Tecnologia e Sociedade, v. 2, p. 194-210, 2011.

REIS, Verusca Moss S. Do 'Gênio Maligno' ao Fetiche do Fast Food Acadêmico. Demetra, V. 7, p. 59-64, 2012.

REIS, Verusca Moss S. O Problema do Ethos Científico no Novo Modo de Produção da Ciência Contemporânea. Rio de Janeiro: Universidade do Estado do Rio de Janeiro (Tese de $\mathbb{D}$ outorado), 2010.

REIS, Verusca Moss Simões dos; VIDEIRA, Antonio Augusto Passos. John Ziman e a ciência pós-acadêmica: consensibilidade, consensualidade e confiabilidade. Sci. stud., São Paulo, v. 11, n. 3, p. 583-611, 2013.

REIS, Verusca Moss, S. O Problema do Ethos Científico no Novo Modo de Produção da Ciência Contemporânea. Tese de Doutorado. Rio de Janeiro: Universidade do Estado do Rio de Janeiro, 2010.

REIS, Verusca. Moss S. A Lenda Cognitiva na Filosofia da Ciência Segundo John Michael Ziman. In: Antonio Augusto Passos Videira. (Org.). Perspectivas Contemporâneas em Filosofia da Ciência. Rio de Janeiro: EDUERJ, 2012, p. 100. 
SCHRÖDINGER, Erwin. A Natureza e os Gregos seguido de Ciência e Humanismo. Lisboa: Edições 70, 1996.

SCHWARTZMAN, Simon. Um espaço para a ciência - a formação da comunidade científica no Brasil. Campinas, SP: Editora Unicamp, 2015.

SILVA, Vinícius Carvalho. A interpretação filosófica da mecânica quântica de Werner Heisenberg: Ontologia matemática e crise nos fundamentos da lógica clássica. Dissertação de Mestrado. Rio de Janeiro: Universidade do Estado do Rio de Janeiro, 2012.

SILVA, Vinícius Carvalho. Os microscópios de Galison e os telescópios de Jammer: qual imagem de ciência nos interessa mais? In: Scientiarum Historia VIII, 2015, Rio de Janeiro. Filosofia, Ciências e Artes: conexões interdisciplinares - (In)certezas e (In)completudes. Rio de Janeiro: UFRJ-HCTE, 2015.v. 1. p. 44.

Teoria quântica, Física Nuclear e Filosofia Grega. Griot: Revista de Filosofia V.15, n.1, junho/2017. pp. 2233-250.

SILVA, Vinícius Carvalho; BEGALLI, Márcia.; Hands on CERN/RIO. in CROLAR Critical Reviews on Latin American Research: "Science, Technology, Society - and the Americans?", Vol. 5, No. 1, April 2016, pp. 84-87, Berlin: Lateinamerika-Institut of the FreieUniversitåt Berlin.

VIDEIRA, Antonio Augusto Passos (Org.). Henrique Morize. Rio de Janeiro: Fundação Miguel de Cervantes, 2012.

VIDEIRA, Antonio Augusto Passos. A inevitabilidade da Filosofia na Ciência Natural do século 19: O caso da física teórica. Ijuí: Ed. da Unijuí, 2013.

VIDEIRA, Antonio Augusto Passos. Henrique Morize e o ideal de ciência pura na República Velha. Rio de Janeiro: Editora FGV, 2003.

VIDEIRA, Antonio Augusto Passos. História do Observatório Nacional' a persistente construção de uma identidade científica. Rio de Janeiro: Observatório Nacional, 2007.

VIDEIRA, Antonio Augusto Passos. MENDONÇA, André Luís de Oliveira. Contextualizing the Contexts of Discovery and Justification: How to do Science Studies in Brazil In Brazilian studies in Philosophy and History of Science. Springer, 2011.

VIDEIRA, Antonio Augusto Passos. Metafísica, Físicos, Valores: Um ensaio sobre a crise dos fundamentos das ciências naturais na passagem do século XIX para o século XX. Ensaios Filosóficos, Volume IV - outubro/2011

VIDEIRA, Antonio Augusto Passos. Filosofia da Ciência sob o signo dos Science Studies FILOSOFIA. in Abstracta 2: 1 pp. 70 - 83, 2005.

VIDEIRA, Antonio Augusto Passos. Historiografia e História da Ciência in Escritos: Revista da Casa de Rui Barbosa. Ano 1, n.1. 2007.

WEBER, Max. A ciência como vocação. Arthur Morão (Trad.). Lusofia [on line], p. 4.

Doutor em Filosofia (UERT, 2017)

Professor do Departamento/Curso Filosofia (UFT) Pós-Doutorando do Instituto de Medicina Social da UERT

E-mail: viniciusfillo@yahoo.com.br 